\title{
FAKTOR-FAKTOR YANG MEMPENGARUHI PENDERITA HIPERTENSI DALAM MENGGUNAKAN OBAT NONFARMAKOLOGI DI WILAYAH KERJA PUSKESMAS CEMPAE KOTA PAREPARE
}

\section{Factors Affecting Hypertensive Patients Using Non-Pharmacological Drugs in the Work Area of Cempae Community Health Center Parepare City.}

\author{
Nursyafitri, Abidin, Amir Patintingan \\ Program Studi Kesehatan Masyarakat Fakultas Ilmu Kesehatan Universitas Muhammadiyah \\ Parepare \\ (fitri.fikes@gmail.com 082349414808)
}

\begin{abstract}
ABSTRAK
Obat Nonfarmakologi adalah obat tradisional yang menggunakan bahan-bahan alami yang mudah didapat karena bisa ditemukan disekitar lingkungan, dimana pengobatan nonfarmakologi memiliki kelebihan dalam banyak hal, serta tidak memiliki efek samping bagi tubuh. Beberapa faktor-faktor yang mempengaruhi penderita hipertensi dalam menggunakan obat nonfarmakologi adalah tingkat pengetahuan, perilaku, kepercayaan. Penelitian ini bertujuan untuk menjelaskan Faktor-Faktor yang Mempengaruhi Penderita Hipertensi dalam Menggunakan Obat NonFarmakologi di Wilayah Kerja Puskesmas Cempae Kota Parepare, serta memberikan informasi yang selama ini mereka belum pahami secara jelas. Penelitian ini menggunakan cross sectional. Lokasi penelitian dilakukan di Wilayah Kerja Pusekesmas Cempae Kota Parepare. Adapun waktu penelitian dilakukan pada bulan Juni-Juli 2018. Populasinya adalah penderita hipertensi dengan pengambilan sampel yaitu accidental sampling dengan jumlah 100 sampel. Hasil penelitian menunjukkan bahwa ada pengaruh tingkat pengetahuan $(0,035<0,05)$, perilaku $(0,004<0,05)$, dan kepercayaan $(0,023<0,05)$, penderita hipertensi dalam menggunakan obat nonfarmakologi di Wilayah Kerja Puskesmas Cempae Kota Parepare.
\end{abstract}

Kata kunci : Hipertensi, obat nonfarmakologi, pengetahuan, perilaku, kepercayaan

\begin{abstract}
Nonfarmakologi medicine is a traditional medicine that uses natural ingredients that are easily available because it can be found around the environment, where non-pharmacological treatment has advantages in many ways, and has no side effects on the body. Some of the factors that influence hypertension sufferers in using non-pharmacological drugs are the level of knowledge, behavior, trust. This study aims to explain the Factors Affecting Patients with Hypertension in Using Non-Pharmacological Drugs in the Work Area of the Cempae Health Center in the City of Parepare, as well as providing information that they have not yet understood clearly. This study uses cross sectional. The location of the study was carried out in the Community Health Center in the City of Parepare. The time of the study was conducted in JuneJuly 2018. The population was hypertensive patients with sampling that was accidental sampling with a total of 100 samples. The results showed that there was an influence of the level of knowledge $(0.035<0.05)$, behavior $(0.004<0.05)$, and trust $(0.023<0.05)$, hypertensive patients using non-pharmacological drugs in the Work Area of Cempae Community Health Center, Parepare City.
\end{abstract}

Keywords : Hypertension, non-pharmacological medicine, knowledge, behavior, trust 



\section{PENDAHULUAN}

Hipertensi adalah suatu keadaan ketika tekanan darah di pembuluh darah meningkat secara terus menerus. Hal tersebut dapat terjadi karena jantung bekerja lebih keras memompa darah untuk memenuhi kebutuhan oksigen dan nutrisi tubuh. Jika mmHg atau tekanan darah diastolik $\geq 90 \mathrm{mmHg} .{ }^{1}$

Penyakit hipertensi merupakan gejala peningkatan tekanan darah yang kemudian berpengaruh pada organ yang lain, seperti stroke untuk otak atau penyakit jantung koroner untuk pembuluh darah jantung dan otot jantung. Penyakit ini menjadi salah satu masalah utama dalam ranah kesehatan masyarakat maupun dunia. Diperkirakan sekitar $80 \%$ kenaikan kasus hipertensi terutama terjadi di negara berkembang pada tahun 2025 dari jumlah total 639 juta kasus di tahun 2000. Jumlah ini diperkirakan meningkat menjadi 1,15 miliar kasus di tahun 2025. Prediksi ini didasarkan pada angka penderita hipertensi dan pertambahan penduduk saat ini. ${ }^{2}$

Menurut data WHO (World Health Organization) pada tahun 2013, di seluruh dunia sekitar 972 juta orang atau 26,4\% orang di seluruh dunia mengidap hipertensi, angka ini kemungkinan akan meningkat menjadi 29,2\% di tahun 2025. Dari 972 juta pengidap hipertensi, 333 juta berada di negara maju (Amerika Serikat, Kanada, Jepang, Korea Selatan dan lainnya) dan 639 sisanya berada di negara berkembang (India, Malaysia, Korea Utara, Indonesia dan lainnya). ${ }^{3}$ Penyakit terbanyak pada usia lanjut berdasarkan Riset Kesehatan Dasar tahun 2013 adalah hipertensi. dengan prevalensi $45,9 \%$ pada usia 55-64 tahun, $57,6 \%$ pada usia $65,74 \%$ dan $63,8 \%$ pada usia $\geq 75$ tahun.

Di dunia Internasional, penggunaan obat Nonfarmakologi sudah sangat berkembang, cenderung meningkat, dan diperhitungkan sebagai komponen penting dalam pelayanan kesehatan dasar sejak dikeluarkannya Deklarasi Alma-Ata tahun 1978 dan dibentuknya program pengobatan tradisional oleh WHO (World Health Organization). Keseriusan pemerintah mendukung pemanfaatan obat nonfarmakologi terlihat dari berbagai peraturan yang ada, terutama sejak dikeluarkannya Peraturan Menteri Kesehatan tentang Saintifikasi Jamu pada tahun $2010 .^{4}$

Penggunaan obat nonfarmakologi sebagai bagian dari pengobatan hipertensi semakin meningkat dalam dekade terakhir. Hal ini disebabkan adanya beberapa faktor, terutama harga obat nonfarmakologi yang dianggap lebih murah dengan efek samping yang dianggap lebih sedikit. ${ }^{5}$

Riset Kesehatan Dasar tahun 2013 yang diselenggarakan oleh Kementrian Kesehatan menunjukkan bahwa prevalensi hipertensi di Indonesia sangat tinggi, yaitu $25,8 \%$ dari total penduduk dewasa dengan $62,3 \%$ kasus diantaranya tidak terdeteksi oleh pelayanan Kesehatan. Di Jawa Tengah, prevalensi hipertensi mencapai $26,4 \%$ untuk usia lebih dari 18 tahun. Di Kota Semarang, diketahui bahwa penyakit hipertensi 
merupakan penyakit dengan angka kejadian tertinggi selama lima tahun berturut-turut untuk kategori panyakit tidak menular dengan prevalensi tahun 2013 sebesar $48,4 \%$

Seiring dengan kemajuan teknologi banyak metode pengobatan yang berkembang di dunia. Banyak pengobatan non farmakologi yang telah ditemukan untuk membantu menurunkan tekanan darah diantaranya tanaman tradisonal, akupunktur, akupressur, bekam, pijat refleksi, hipnoterapi, dan lain-lain. Sesuai dengan peraturan mentri kesehatan republik Indonesia nomor

\section{9/MENKES/PER/IX/2007} tentang

penyelenggaraan pengobatan komplementer alternatif di fasilitas pelayanan kesehatan. Pengobatan komplementer dilakukan sebagai upaya pelayanan yang berkesinambungan mulai dari promotif, preventif, kuratif, dan atau rehabilitatif. Praktik mandiri pengobatan komplementer alternatif dilakukan oleh tenaga kesehatan tersertifikasi sering dijumpai di lingkungan sekitar. Sehingga masyarakat kini mulai memilih pengobatan non farmakologi, karena mengetahui efek samping dari penggunaan farmakologi yang dapat merusak hati dan ginjal jika digunakan dalam jangka waktu yang lama. Pengobatan non farmakologi yang sering dipilih oleh penderita hipertensi adalah pengobatan nonfarmakologi.

Persentase tekanan darah tinggi/hipertensi di Sulawesi Selatan tahun 2016 sebanyak 21,90\%, dengan kasus tertinggi di Kabupaten Selayar (32,49\%), Kabupaten Soppeng (24,92\% dan Kabupaten Takalar (14,82\%), adapun kasus terendah di kabupaten Sidrap, Kabupaten Luwu, dan Kota Makassar masing-masing $(0,00 \%){ }^{6}$ Jumlah penderita hipertensi di Kota Parepare berbasis puskesmas pada tahun 2015-2016 sebanyak 4,266 penderita, yang terbanyak adalah perempuan sebanyak 2,239. Jumlah penderita hipertensi berdasarkan tahun di Dinas Kesehatan Kota Parepare yang terbesar kejadian hipertensi adalah pada tahun 2016. Pengetahuan merupakan domain yang sangat penting dalam membentuk tindakan seseorang (overt behavior). Perilaku yang didasari dengan pengetahuan akan lebih langgeng dibandingkan perilaku yang tidak didasarkan pada pengetahuan. ${ }^{7}$ Beberapa hasil penelitian sebelumnya menyatakan bahwa beberapa faktor yang berhubungan dengan pemanfaatan pengobatan tradisional yaitu umur, jenis kelamin, pendidikan, pekerjaan , sikap, pengetahuan, kepercayaan, perilaku, inilah yang dapat mempengaruhi penderita hipertensi dalam menggunakan obat nonfarmakologi. Berdasarkan latar belakang inilah peneliti tertarik mengkaji tentang faktor-faktor yang mempengaruhi penderita hipertensi dalam penggunaan obat nonfarmakologi di Wilayah Kerja Puskesmas Cempae Kota Parepare.

\section{BAHAN DAN METODE}

Metode penelitian yang digunakan adalah penelitian survei analitik, dengan pendekatan Cross Sectional study. Lokasi 
penelitian ini dilakukan di wilayah Kerja Puskesmas Cempae Kota Parepare. Adapaun waktu penelitian pada bulan Juni-Juli 2018. Instrumen dalam penelitian adalah kuesioner. Populasi pada penelitian ini merupakan seluruh penderita hipertensi yang berusia < 35-> 75 tahun yang termasuk dalam Wilayah Kerja Puskesmas Cempae. Adapun teknik pengambilan sampel dalam penelitian ini dilakukan melalui teknik sistem accidental sampling, dengan sampel berjumlah 100 orang. Analisis data univariat menggunakan teknik statistik deskriptif yaitu memperoleh informasi secara umum tentang semua variabel penelitian yaitu pengetahuan, perilaku dan kepercayaan dalam menggunakan obat nonfarmakologi hipertensi. Analisis bivariat dilakukan dengan menggunakan uji chi square (x2). Uji chi square yakni analisis yang digunakan untuk mengetahui pengaruh antara variabel devendent dan variabel independen. Dasar pengambilan keputusan penerimaan hipotesis penelitian berdasarkan tingkat signifikan (nilai $p$ ), dimana terdapat peluang (bermakna) apabila nilai $\mathrm{p}<0,05$ dan tidak ada peluang apabila $\mathrm{p}>0,05$. 


\section{HASIL}

Analisis karakteristik responden ini menggunakan distribusi tabel dengan data yang diperoleh dari kuesioner yang berdasarkan umur, jenis kelamin, pendidikan terakhir pada penderita hipertensi di Wilayah Kerja Puskesmas Cempae Kota Parepare. Tabel 1 dapat kita lihat bahwa umur rata-rata 35-54 tahun 60,0\%, jenis kelamin perempuan $94,0 \%$, dengan pendidikan terakhir SD 60,0\%.

Tabel 2 dapat kita lihat distribusi analisis variabel bahwa dari 100 responden penderita hipertensi di Wilayah Kerja Puskesmas Cempae Kota Parepare, berdasarkan responden yang menggunakan obat nonfarmakologi yaitu $67,0 \%$, sedangkan yang tidak menggunakan obat nonfarmakologi yaitu 33,0\%. Berdasarkan tingkat pengetahuan responden tinggi sebanyak 49,0\%, tingkat pengetahuan sedang sebanyak 20,0\%, sedangkan responden sengan tingkat pengetahuan rendah sebanyak 31,0\%. Berdasarkan responden dengan perilaku baik sebanyak $64,0 \%$, perilaku cukup sebanyak 25,0\%, sedangkan responden dengan perilaku buruk sebanyak 11,0\%. Berdasarkan responden dengan kepercayaan yang percaya sebanyak $16,0 \%$, kepercayaan yang kurang percaya sebanyak 79,0\%, sedangkan responden dengan kepercayaan yang tidak percaya sebanyak $5,0 \%$.

Tabel 3 menggambarkan pengaruh tingkat pengetahuan terhadap penderita hipertensi dalam menggunakan obat nonfarmakologi, diperoleh hasil berdasarkan tingkat pengetahuan yaitu ya menggunakan obat nonfarmakologi dimana kategori pengetahuan tinggi yaitu sebanyak 36 responden atau $73,5 \%$, sedang sebanyak 15 responden atau $75,0 \%$, rendah sebanyak 16 responden atau $51,6 \%$. Tidak menggunakan obat nonfarmakologi dimana kategori pengetahuan tinggi yaitu sebanyak 13 responden atau $26,5 \%$, sedang sebanyak 5 responden atau $25,0 \%$, rendah sebanyak 15 responden atau 48,4\%. Berdasarkan hasil uji chi-square di peroleh nilai $p$ value $(0,035)<$ $\alpha(0,05)$, maka $\mathrm{H}_{\mathrm{a}}$ diterima dan $\mathrm{H}_{0}$ ditolak sehingga disimpulkan bahwa ada pengaruh yang signifikan antara tingkat pengetahuan terhadap penderita hipertensi dalam menggunakan obat nonfarmakologi di wilayah kerja puskesmas cempae kota Parepare.

Tabel 4 Menunjukkan bahwa dari 100 responden dari hasil penelitian yang dilakukan di wilayah kerja puskesmas cempae kota parepare, diperoleh hasil berdasarkan perilaku yaitu ya menggunakan obat nonfarmakologi dimana kategori perilaku baik yaitu sebanyak 49 responden atau $76,6 \%$, cukup sebanyak 15 responden atau $60,0 \%$, buruk sebanyak 3 responden atau $27,3 \%$. Tidak menggunakan obat nonfarmakologi dimana kategori perilaku baik yaitu sebanyak 15 responden atau $23,4 \%$, cukup sebanyak 10 responden atau $40,0 \%$, rendah sebanyak 8 responden atau $72,7 \%$. Berdasarkan hasil uji chi-square di peroleh nilai $p$ value $(0,004)<\alpha(0,05)$, maka $\mathrm{H}_{\mathrm{a}}$ diterima dan $\mathrm{H}_{0}$ ditolak sehingga disimpulkan bahwa ada pengaruh yang 
signifikan antara tingkat pengetahuan terhadap penderita hipertensi dalam menggunakan obat nonfarmakologi di wilayah kerja puskesmas cempae kota Parepare.

Tabel 5. Menunjukkan bahwa dari 100 responden dari hasil penelitian yang dilakukan di wilayah kerja puskesmas cempae kota parepare, diperoleh hasil berdasarkan perilaku yaitu ya menggunakan obat nonfarmakologi dimana kategori kepercayaan percaya yaitu sebanyak 12 responden atau $75,0 \%$, kurang percaya sebanyak 54 responden atau $68,4 \%$, tidak percaya sebanyak 1 responden atau $20,0 \%$. Tidak menggunakan obat nonfarmakologi dimana kategori kepercayaan percaya yaitu sebanyak 4 responden atau $25,0 \%$, kurang percaya sebanyak 25 responden atau $31,6 \%$, tidak percaya sebanyak 4 responden atau $80,0 \%$. Berdasarkan hasil uji chi-square di peroleh nilai $p$ value $(0,023)<\alpha(0,05)$, maka $\mathrm{H}_{\mathrm{a}}$ diterima dan $\mathrm{H}_{0}$ ditolak sehingga disimpulkan bahwa ada pengaruh yang signifikan antara tingkat pengetahuan terhadap penderita hipertensi dalam menggunakan obat nonfarmakologi di wilayah kerja puskesmas cempae kota Parepare.

\section{PEMBAHASAN}

Pengetahuan merupakan salah satu pendorong untuk mengubah perilaku atau mempebaiki perilaku seseorang yang lebih baik dari sebelumnya. Pengetahuan tentang pola konsumsi mempunyai faktor yang menentukan seseorang berperilaku tidak sehat menjadi sehat. Pengetahuan dapat diperoleh dari pengalaman dan proses belajar baik formal maupun informal. Perilaku manusia merupakan hasil dari berbagai macam pengalaman serta interkasi manusia dengan lingkungannya yang terwujud dalam bentuk pengetahuan, sikap dan tindakan.

Berdasarkan tingkat pengetahuan, Menunjukkan bahwa dari 100 responden dari hasil penelitian yang dilakukan di wilayah kerja puskesmas cempae kota parepare, diperoleh hasil berdasarkan tingkat pengetahuan yaitu ya menggunakan obat nonfarmakologi dimana kategori pengetahuan tinggi yaitu sebanyak 36 responden atau 73,5\%, sedang sebanyak 15 responden atau $75,0 \%$, rendah sebanyak 16 responden atau 51,6\%. Tidak menggunakan obat nonfarmakologi dimana kategori pengetahuan tinggi yaitu sebanyak 13 responden atau $26,5 \%$, sedang sebanyak 5 responden atau $25,0 \%$, rendah sebanyak 15 responden atau 48,4\%. Dari hasil analisis bivariat ditemukan bahwa ada pengaruh yang signifikan antara tingkat pengetahuan penderita hipertensi dalam menggunakan obat nonfarmakologi di wilayah kerja puskesmas cempae kota parepare. Berdasarkan hasil uji chi-square di peroleh nilai $p$ value $(0,035)<\alpha(0,05)$, maka $H_{a}$ diterima dan $\mathrm{H}_{0}$ ditolak sehingga disimpulkan bahwa ada pengaruh yang signifikan antara tingkat pengetahuan terhadap penderita hipertensi dalam menggunakan obat nonfarmakologi di 
wilayah kerja puskesmas cempae kota Parepare.

Penelitian lain yang sejalan adalah penelitian Ani Astuti (2016) dimana hasil penelitiannya menyatakan bahwa tingkat pengetahuan memiliki hubungan terhadap penggunaan obat tradisional. ${ }^{8}$

Dari segi biologis perilaku adalah kegiatan atau aktivitas organisme (makhluk hidup) yang bersangkutan. Oleh sebab itu, dari sudut pandang biologis semua makhluk hidup itu berperilaku karena mereka memiliki aktivitas masing-masing. Sehingga yang dimaksud dengan perilaku manusia, pada hakikatnya adalah tindakan atau aktivitas dari manusia itu sendiri yang mempunyai bentangan yang sangat luas anatar lain: berjalan, berbicara, membaca, menangis, tertawa, bekerja, kuliah, menulis, dan sebagainya. Dari uraian ini dapat disimpulkan bahwa yang dimaksud perilaku manusia adalah semua kegiatan yang tidak dapat diamati oleh pihak luar.

Berdasarkan perilaku, menunjukkan bahwa dari 100 responden dari hasil penelitian yang dilakukan di wilayah kerja Puskesmas Cempae Kota Parepare, diperoleh hasil berdasarkan perilaku yaitu ya menggunakan obat nonfarmakologi dimana kategori perilaku baik yaitu sebanyak 49 responden atau $76,6 \%$, cukup sebanyak 15 responden atau $60,0 \%$, buruk sebanyak 3 responden atau $27,3 \%$. Tidak menggunakan obat nonfarmakologi dimana kategori perilaku baik yaitu sebanyak 15 responden atau $23,4 \%$, cukup sebanyak 10 responden atau $40,0 \%$, rendah sebanyak 8 responden atau $72,7 \%$. Berdasarkan hasil uji chi-square di peroleh nilai $p$ value $(0,004)<\alpha(0,05)$, maka $\mathrm{H}_{\mathrm{a}}$ diterima dan $\mathrm{H}_{0}$ ditolak sehingga disimpulkan bahwa ada pengaruh yang signifikan antara tingkat pengetahuan terhadap penderita hipertensi dalam menggunakan obat nonfarmakologi di wilayah kerja Puskesmas Cempae Kota Parepare.

Penelitian yang sejalan dengan penelitian kali ini adalah penelitian Asriullah Jabbar, Musdalipah, Andi Nurwati dimana hasil penelitiannya menyatakan bahwa tingkat pengetahuan memiliki hubungan terhadap penggunaan obat tradisional. Kepercayaan adalah anggapan (keyakinan), sesuatu yang dipercayai (dianggap benar), harapan dan keyakinan. Kepercayaan diri adalah keyakinan bahwa dirinya boleh mengendalikan kehidupan dengan baik serta segala cobaan yang dihadapi dengan jayanya. $^{9}$

Berdasarkan hasil penelitian kepercayaan, Menunjukkan bahwa dari 100 responden dari hasil penelitian yang dilakukan di wilayah kerja puskesmas cempae kota parepare, diperoleh hasil berdasarkan perilaku yaitu ya menggunakan obat nonfarmakologi dimana kategori kepercayaan percaya yaitu sebanyak 12 responden atau $75,0 \%$, kurang percaya sebanyak 54 responden atau $68,4 \%$, tidak percaya sebanyak 1 responden atau 20,0\%. Tidak menggunakan obat nonfarmakologi dimana kategori kepercayaan percaya yaitu sebanyak 4 responden atau 25,0\%, kurang percaya sebanyak 25 responden atau $31,6 \%$, 
tidak percaya sebanyak 4 responden atau $80,0 \%$. Berdasarkan hasil uji chi-square di peroleh nilai $p$ value $(0,023)<\alpha(0,05)$, maka $\mathrm{H}_{a}$ diterima dan $\mathrm{H}_{0}$ ditolak sehingga disimpulkan bahwa ada pengaruh yang signifikan antara tingkat pengetahuan terhadap penderita hipertensi dalam menggunakan obat nonfarmakologi di wilayah kerja puskesmas cempae kota Parepare.

Hal ini sejalan dengan penelitian Mulyadi (2005) bahwa kepercayaan ada hubungannya dengan pengobatan tradisional herbalis, dimana orang dengan tingkat kepercayaan tinggi memiliki peluang 2.58 kali lebih besar menggunakan pengobatan tradisional dibanding orang dengan kepercayaan rendah. ${ }^{10}$ Penelitian lain yang sejalan adalah penelitian Yenni Fajri (2013) dimana hasil penelitiannya menyatakan bahwa kepercayaan memiliki hubungan terhadap penggunaan obat tradisional. ${ }^{9}$

\section{KESIMPULAN DAN SARAN}

Berdasarkan hasil penelitian dari faktor-faktor yang mempengaruhi penderita hipertensi dalam menggunakan obat nonmarmakologi di Wilayah Kerja

\section{DAFTAR PUSTAKA}

1. Kasper DL, Hauser SL, Jameson JL, Fauci AS, Longo DL, Loscalzo J. Harrison's Principles of Internal Medicine. Nineteenth Edition. New York: McGraw Hill Education; 2015: 1669-1680.
Puskesmas Cempae Kota Parepare. Dapat disimpulkan bahwa ada pengaruh tingkat pengetahuan terhadap penderita hipertensi tehadap penggunaan obat nonfarmakologi, ada pengaruh perilaku terhadap penderita hipertensi terhadap penggunaan obat nonfarmakologi dan ada pengaruh kepercayaan terhadap penderita hipertensi terhadap penggunaan obat nonfarmakologi. Berdasarkan kesimpulan maka penulis menyarankan penderita hipertensi diharapkan dapat mengetahui informasi yang benar tentang penggunaan obat tradisional untuk hipertensi sehingga dapat mengaplikasikan sendiri terhadap diri sendiri maupun ke orang lain. Bagi Institusi kesehatan dapat menjadikan hasil penilitian ini sebagai bahan masukan untuk mengembangkan ilmu pengetahuan tentang hubungan pengetahuan, perilaku dan kepercayaan dalam menggunakan obat pada penderita hipertensi. Diharapkan untuk peneliti selanjutnya dapat melakukan lebih lanjut tentang faktor-faktor apa saja yang dapat dilakukan penderita hipertensi dalam menggunakan obat nonfarmakologi supaya dapat mencegah hipertensi.

2. Ardiansyah M. Medikal Bedah Untuk Mahasiswa. Yogyakarta : Diva Press; 2012.

3. Yonata, A., Satria, A. Hipertensi sebagai Faktor Pencetus Terjadinya Stroke; 2016.

4. Delima D, Widowati L, Astuti Y, Siswoyo H, Gitawati R, Purwadianto A. Gambaran Praktik Penggunaan Jamu 
Oleh Dokter di Enam Provinsi di Indonesia. Jakarta: Buletin Penelitian Kesehatan; 2012: 40(3): 109- 122.

5. Hussaana A, Sarosa H, Indrayani UD, Chodidjah C, Widiyanto B, Pertiwi D. Formula Jamu Antihipertensi and Captopril are Equally Effective in Patients with Hypertension. Universa Medicina; 2016:35(2): 81-88.

6. Profil Kesehatan Provinsi Sulawesi Selatan tahun 2016. [serial online]. 2016. [Diakses tanggal 30 Juni 2018]. Available at http://www.depkes.go.id/resources/dow nload/profil/PROFIL_KES_PROVINSI _2016/27_Sulsel_2016.pdf

7. Notoatmodjo, Soekidjo. Promosi Kesehatan dan Perilaku Kesehatan. Jakarta: Rineka Cipta; 2012.

8. Astuti, Ani . Tiga Faktor Penggunaan Obat Herbal Hipertensi di Kota Jambi. Jambi; 2016.
9. Yenni Fajri. Hubungan Pengetahuan dan Kepercayaan dengan Penggunaan Obat Pada Penderita Hipertensi di Desa Lamga Kecamatan Mesjid Raya Kabupaten Aceh Besar. 2013.

10. Mulyadi. Analisis Faktor-Faktor yang Mempengaruhi Keluarga Menggunakan Pengobatan Tradisional Herbalis dalam Mengatasi Masalah Kesehatan di Dewa Warujaya Parung Bogor. Tesis. Fakultas Ilmu Keperawatan. Universitas Indonesia; 2005.

11. Usman, Usman, Makhrajani Majid, and Rasidah Wahyuni Sari. "Faktor-Faktor Yang Berpengaruh Terhadap Kejadian Hipertensi Pada Lansia di Wilayah Kerja Puskesmas Maiwa Kab. Enrekang." Jurnal Ilmiah MANUSIA DAN KESEHATAN 2.1 (2019): 68-79. 


\section{LAMPIRAN}

Tabel 1. Distribusi responden berdasarkan Karakteristik Umum pada Penderita Hipertensi di Wilayah Puskesmas Cempae Kota Parepare

\begin{tabular}{lll}
\hline Karakteristik & Frekuensi (f) & Persentase(\%) \\
\hline Umur & & \\
35-54 tahun & 60 & 60,0 \\
55-74 tahun & 40 & 40,0 \\
\hline Jenis Kelamin & & 6,0 \\
Laki-laki & 6 & 94,0 \\
Perempuan & 94 & \\
\hline Pendidikan & & 60,0 \\
SD & 60 & 29,0 \\
SMP & 29 & 10,0 \\
SMA & 10 & 1,0 \\
S1 & 1 & 100,0 \\
\hline Total & 100 & \\
\hline
\end{tabular}

Sumber : Data Primer, 2018

Tabel 2. Distribusi responden berdasarkan variabel penelitian Menggunakan Obat Nonfarmakologi pada Penderita Hipertensi di Wilayah Kerja Puskesmas Cempae Kota Parepare

\begin{tabular}{|c|c|c|}
\hline Variabel & Frekuensi & Persen \\
\hline \multicolumn{3}{|c|}{ Menggunakan obat nonfarmakologi } \\
\hline Menggunakan & 67 & 67,0 \\
\hline Tidak menggunakan & 33 & 33,0 \\
\hline \multicolumn{3}{|l|}{ Tingkat pengetahuan } \\
\hline Tinggi & 49 & 49,0 \\
\hline Sedang & 20 & 20,0 \\
\hline Rendah & 31 & 31,0 \\
\hline \multicolumn{3}{|l|}{ Perilaku } \\
\hline Baik & 64 & 64,0 \\
\hline Cukup & 25 & 25,0 \\
\hline Buruk & 11 & 11,0 \\
\hline \multicolumn{3}{|l|}{ Kepercayaan } \\
\hline Percaya & 16 & 16,0 \\
\hline Kurang percaya & 79 & 79,0 \\
\hline Tidak percaya & 5 & 5,0 \\
\hline Total & 100 & 100,0 \\
\hline
\end{tabular}

Sumber : Data Primer, 2018 
Tabel 3. Pengaruh Tingkat Pengetahuan terhadap Penderita Hipertensi terhadap Penggunaan Obat Nonfarmakologi di Wilayah Kerja Puskesmas Cempae Kota Parepare

\begin{tabular}{|c|c|c|c|c|c|c|c|}
\hline \multirow{3}{*}{$\begin{array}{c}\text { Tingkat Pengetahuan } \\
\text { Penderita }\end{array}$} & \multicolumn{4}{|c|}{$\begin{array}{c}\text { Menggunakan obat } \\
\text { nonfarmakologi }\end{array}$} & \multirow{2}{*}{\multicolumn{2}{|c|}{ Total }} & \multirow{3}{*}{$\mathbf{P}$} \\
\hline & \multicolumn{2}{|c|}{$\mathrm{Ya}$} & \multicolumn{2}{|c|}{ Tidak } & & & \\
\hline & $\mathrm{n}$ & $\%$ & $\mathrm{~N}$ & $\%$ & $\mathrm{~N}$ & $\%$ & \\
\hline Tinggi & 36 & 73,5 & 13 & 26,5 & 49 & 100,0 & \\
\hline Sedang & 15 & 75,0 & 5 & 25,0 & 20 & 100,0 & 0,035 \\
\hline Rendah & 16 & 51,6 & 15 & 48,4 & 31 & 100,0 & \\
\hline Total & 67 & 67,0 & 33 & 33,0 & 100 & 100,0 & \\
\hline
\end{tabular}

Sumber : Data Primer (2018)

Tabel 4. Pengaruh Perilaku Penderita Hipertensi terhadap Penggunaan Obat Nonfarmakologi di Wilayah Kerja Puskesmas Cempae Kota Parepare

\begin{tabular}{|c|c|c|c|c|c|c|c|}
\hline \multirow{3}{*}{ Perilaku } & \multicolumn{4}{|c|}{$\begin{array}{c}\text { Menggunakan obat } \\
\text { nonfarmakologi }\end{array}$} & \multirow{2}{*}{\multicolumn{2}{|c|}{ Total }} & \multirow{3}{*}{$\mathbf{P}$} \\
\hline & \multicolumn{2}{|c|}{$\mathrm{Ya}$} & \multicolumn{2}{|c|}{ Tidak } & & & \\
\hline & $\mathrm{n}$ & $\%$ & $\mathrm{~N}$ & $\%$ & $\mathrm{n}$ & $\%$ & \\
\hline Baik & 49 & 76,6 & 15 & 23,4 & 64 & 100,0 & \\
\hline Cukup & 15 & 60,0 & 10 & 40,0 & 25 & 100,0 & 0,004 \\
\hline Buruk & 3 & 27,3 & 8 & 72,7 & 11 & 100,0 & \\
\hline Total & 67 & 67,0 & 33 & 33,0 & 100 & 100,0 & \\
\hline
\end{tabular}

Sumber : Data Primer (2018)

Tabel 5. Pengaruh Kepercayaan penderita Hipertensi terhadap Penggunaan Obat Nonfarmakologi di Wilayah Kerja Puskesmas Cempae Kota Parepare

\begin{tabular}{|c|c|c|c|c|c|c|c|}
\hline \multirow{3}{*}{ Kepercayaan } & \multicolumn{4}{|c|}{$\begin{array}{c}\text { Menggunakan obat } \\
\text { nonfarmakologi }\end{array}$} & \multirow{2}{*}{\multicolumn{2}{|c|}{ Total }} & \multirow{3}{*}{$\mathbf{P}$} \\
\hline & \multicolumn{2}{|c|}{$\mathrm{Ya}$} & \multicolumn{2}{|c|}{ Tidak } & & & \\
\hline & $\mathrm{N}$ & $\%$ & $\mathrm{n}$ & $\%$ & $\mathrm{~N}$ & $\%$ & \\
\hline Percaya & 12 & 75,0 & 4 & 25,0 & 16 & 100,0 & \\
\hline Kurang percaya & 54 & 68,4 & 25 & 31,6 & 79 & 100,0 & 0,023 \\
\hline Tidak percaya & 1 & 20,0 & 4 & 80,0 & 5 & 100,0 & \\
\hline Total & 67 & 67,0 & 33 & 33,0 & 100 & 100,0 & \\
\hline
\end{tabular}

Sumber : Data Primer (2018) 